\title{
KAJIAN KINERJA PELAYANAN GENERAL CARGO TERMINAL JAMRUD DI PELABUHAN TANJUNG PERAK SURABAYA
}

\author{
Ayu Fajar Ulfany ${ }^{1}$, Achmad Wicaksono², M. Ruslin Anwar ${ }^{2}$ \\ ${ }^{1}$ Mahasiswa / Program Magister/ Jurusan Teknik Sipil/ Fakultas Teknik Universitas \\ Brawijaya \\ ${ }^{2}$ Dosen / Jurusan Teknik Sipil/ Fakultas Teknik Universitas Brawijaya \\ Jl. MT. Haryono No. 167 Malang, 65145, Jawa Timur \\ Email : ayu.ulfany@gmail.com
}

\begin{abstract}
Terminal Jamrud is a busy terminal among three others terminals run by PT. Pelabuhan Indonesia III branch of Tanjung Perak that serving general goods cargoes and dry bulk both dosmetically and internationally. The source of the problem to increase terminal performance are capacity building, efficiency, productivity and environment. The objectives of this study were to identify the existing performance of loading and unloading of general cargo and to arrange strategies for the development of Terminal Jamrud at Tanjung Perak Port using SWOT analysis. Based on secondary data: 1) the best operational performance of service is the productivity of loading and unloading of general cargo, 2) the best performance is the approach time (AT), 3) the waiting time (TW) has not fulfilled the expected achievement as it is stil below the standard, 4) attributes of utility services, non-container terminal dock facilities, SOR and YOR still needs to be improved. The development strategies of Terminal Jamrud at kuadran I i.e grapid rowth strategy.
\end{abstract}

Keywords : operational performance, IFAS-EFAS SWOT method, general cargo, terminal, port

\section{PENDAHULUAN}

Indonesia sebagai Negara maritim dituntut dapat mengikuti perkembangan dunia internasional menjadi Poros Maritim Dunia, dengan mengembangkan pelabuhan-pelabuhan yang besar dan mendorong investasi dibidang kemaritiman secara besar. Keberlanjutan pengembangan pelabuhan (sustainability port development) menjadi sangat penting, mengingat hampir $80 \%$ total volume perdagangan dunia diangkut melalui laut yang merupakan $70 \%$ dari total nilai perdangan dunia (UNCTAD, 2015). Dari persentase volume sebesar $80 \%$ tersebut Asia menguasai pangsa sebesar $40 \%$ (muat/loaded) - 60\% (bongkar/unloaded).

Terminal Jamrud merupakan terminal yang sibuk diantara tiga terminal lain yang dikelola oleh PT. Pelabuhan Indonesia III (Persero) cabang Tanjung Perak yang melayani jenis muatan barang umun (general cargo) dan curah kering (dry bulk) baik domestik maupun internasional. Kegiatan bongkar muat barang umum dilaksanakan melalui empat tahapan yakni operasi kapal (ship operation), operasi dermaga (quay transfer operation), operasi gudang dan lapangan (storage operation), dan operasi penerimaan \& penyerahan barang (receip \& delivery operaion) (Lasse, 2012). Permasalahan yang teridentifikasi dalam peningkatan kinerja di terminal sering kali bermuara pada permasalahan pengembangan kapasitas, efesiensi, produktivitas dan lingkungan. Produktivitas terminal dibatasi oleh beberapa faktor penting seperti efesiensi penggunaan tenaga kerja, peralatan dan dukungan lahan. (Marzuki, 2008).

Dengan kondisi sarana dan prasarana Terminal Jamrud Pelabuhan Tanjung Perak saat ini tentu berpotensi terjadinya antrian kapal dan menganggu kegiatan bongkar muat. Perlunya suatu kajian guna mengevaluasi kinerja 
bongkar-muat General Cargo Terminal Jamrud di Pelabuhan Tanjung Perak serta menyusun rencana strategi pengembangan di masa yang akan datang. Adapaun Tujuan dari Penelitian ini adalah: Mengetahui kinerja eksisting operasional bongkar muat barang General Cargo dan menentukan strategi-strategi pengembangan kinerja operasional Terminal Jamrud pelabuhan Tanjung Perak untuk optimalisasi pelayanan bongkar muat dengan menggunakan metode analisis SWOT (Strenght, Weakness, Opportunity, Treath).

\section{METODE PENELITIAN}

\subsection{Lokasi Penelitian}

Lokasi penelitian ini ditetapkan di Pelabuhan Tanjung Perak yaitu Terminal Jamrud, yang terdiri dari 3 bagian, yaitu Jamrud Selatan, Jamrud Barat, dan Jamrud Utara. Seperti pada Gambar 1.

\subsection{Metode Pengumpulan Data}

Dalam menganalisis dan mengevaluasi pembahasan pokok dalam penelitian maka diperlukan pengumpulan data sebagai berikut :

1. Observasi, kegiatan ini bertujuan untuk mengetahui permasalah spesifik yang terjadi di lapangan serta tempat-tempat strategis saat pengumpulan data primer

2. Kuisioner, digunakan untuk menganalisis kinerja Terminal Jamrud dari sudut pandang pengguna jasa.

3. Wawancara, dilakukan untuk mengalalisis rencana strategi pengembangan Terminal Jamrud dalam melayani barang General Cargo.

\subsection{Metode Analisis Data}

Dari hasil pengumpulan data di lapangan, kemudian data diolah menggunakan metode, yaitu: Metode Analisis Strengh, Weakness, Opportunity, Treath (SWOT), analisis dilakukan dengan mengumpulkan semua informasi strategis, kemudian memanfaatkan semua informasi tersebut kedalam modelmodel kuantitatif perumusan strategi.

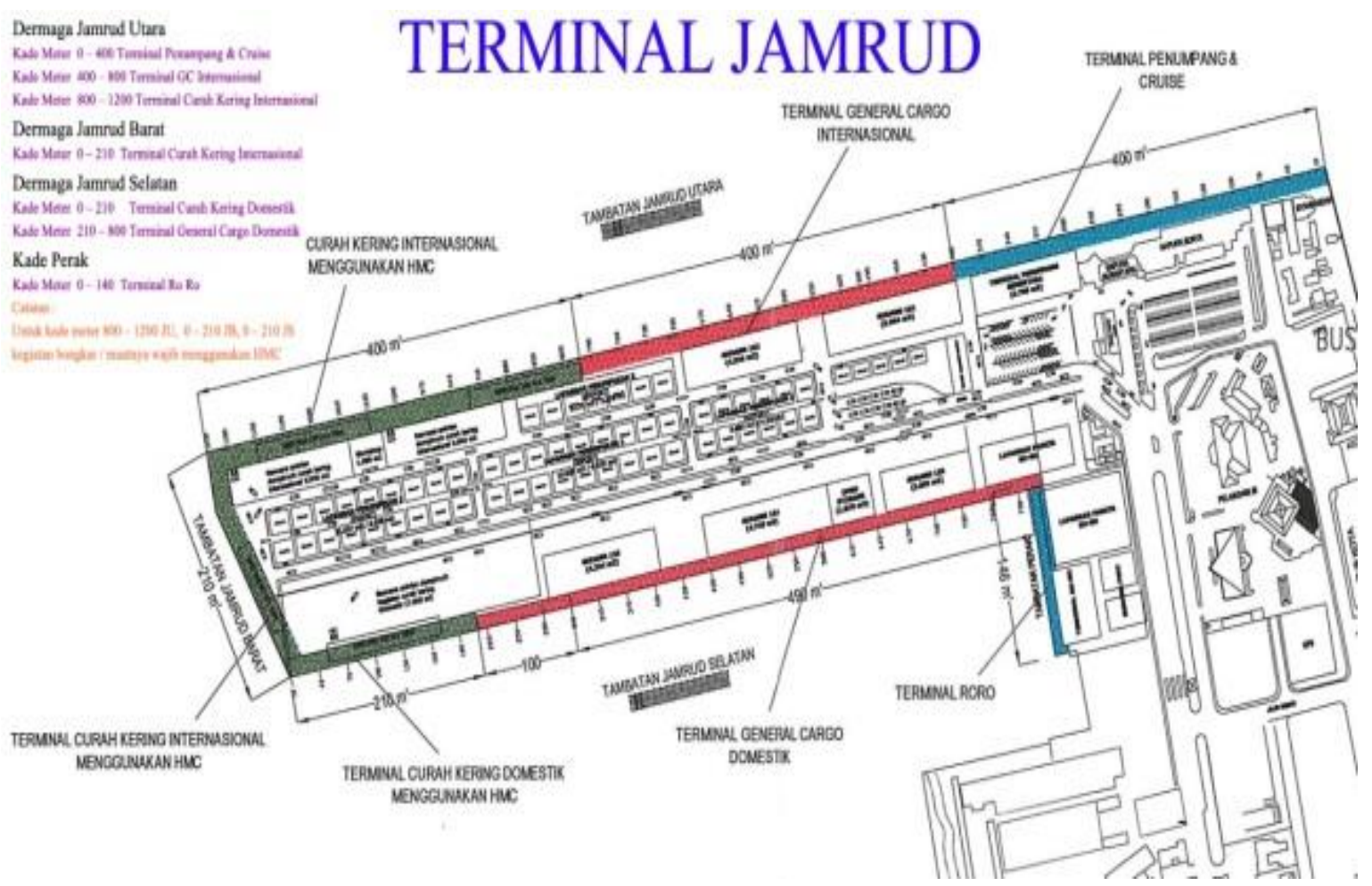

Gambar 1. Terminal Jamrud pelabuhan Tanjung Perak Surabaya 


\section{HASIL ANALISIS DAN PEMBAHASAN}

\subsection{Kondisi Eksisting Kinerja Pelayanan Operasional dan Utilitas Fasilitas Terminal Jamrud}

\subsubsection{Arus kunjungan kapal}

Arus kunjungan kapal dalam negeri dalam satuan Gross Tonage (GT) cenderung mengalami kenaikan, kecuali dari tahun 2014 ke tahun 2015 terjadi penurunan sebesar 10\%. Sedangkan untuk kunjungan kapal luar negeri mengalami penurunan dari tahun 2014 ke tahun 2015 sebesar $30 \%$ atau 2.065.782 GT kemudian cenderung mengalami peningkatan kembali di tahun 2015 sebesar $27 \%$ dan kenaikan $12 \%$ di tahun 2016. Hal ini dikarenakan arus barang impor ke Terminal Jamrud di pelabuhan Tanjung Perak mengalami peningkatan, ditampilkan pada Gambar 2.

\subsubsection{Arus Barang}

Untuk arus barang yang ditangani Terminal Jamrud di pelabuhan Tanjung Perak senantiasa mengalami peningkatan dari tahun

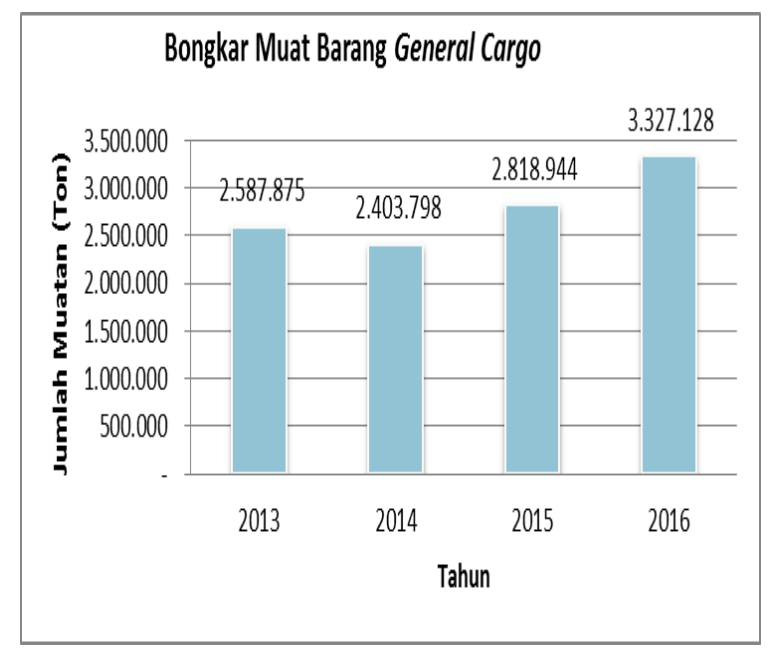

Gambar 2. Arus kunjungan kapal (GT) ke tahun. Arus bongkar muat barang general cargo dari tahun 2014 sampai tahun 2016, ratarata kenaikan sebesar $17 \%-18 \%$ pertahunnya seperti pada Gambar 3.

\subsubsection{Pemenuhan Standart Kinerja Operasional Terminal Jamrud}

Dari hasil penilaian kinerja berdasarkan SK Dirjen Hubla Nomor : HK/103/2/18/DJPL-16, dapat diketahui bahwa : Pelayanan untuk tingkat kinerja paling baik adalah presentase ET:BT dan untuk tingkat kinerja kapal yang kurang baik adalah waiting time dan approach time karena melebihi $10 \%$ dari nilai standart yang telah ditetapkan. Sedangkan tingkat kinerja untuk Pelayanan barang sudah memenuhi pencapaian yang diharapkan karena berada diatas nilai standart yang ditetapakan serta utilitas dermaga terminal non petikemas, SOR dan lapangan penumpukan (YOR) masih harus diperbaiki lagi. Hasil kinerja eksisting operasional dapat dilihat dan pencapaian kinerja operasional Terminal Jamrud dapat dilihat pada Tabel 1.

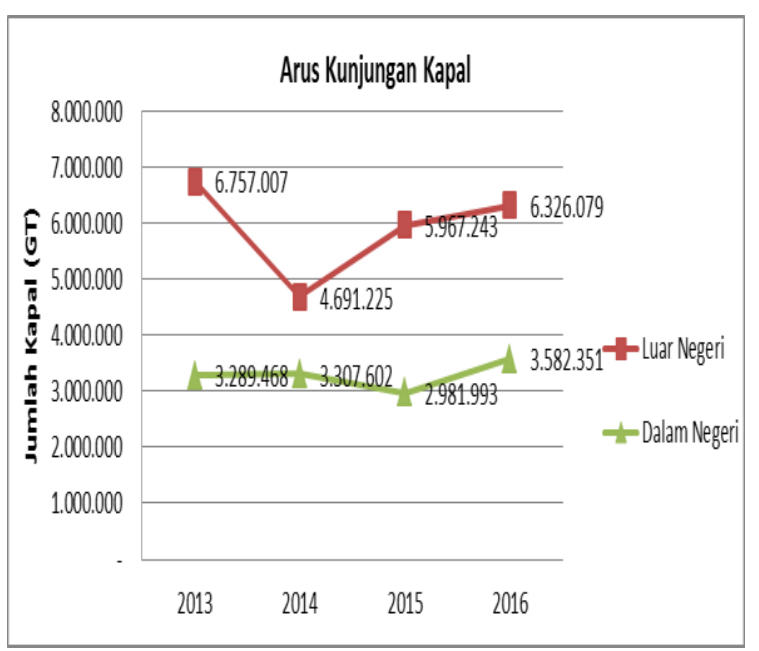

Gambar 3. Arus barang muatan umum (Ton/M3) 
Tabel 1. Pencapaian kinerja operasional utilitas fasilitas serta peralatan Terminal Jamrud dari tahun 2013 sampai tahun 2016

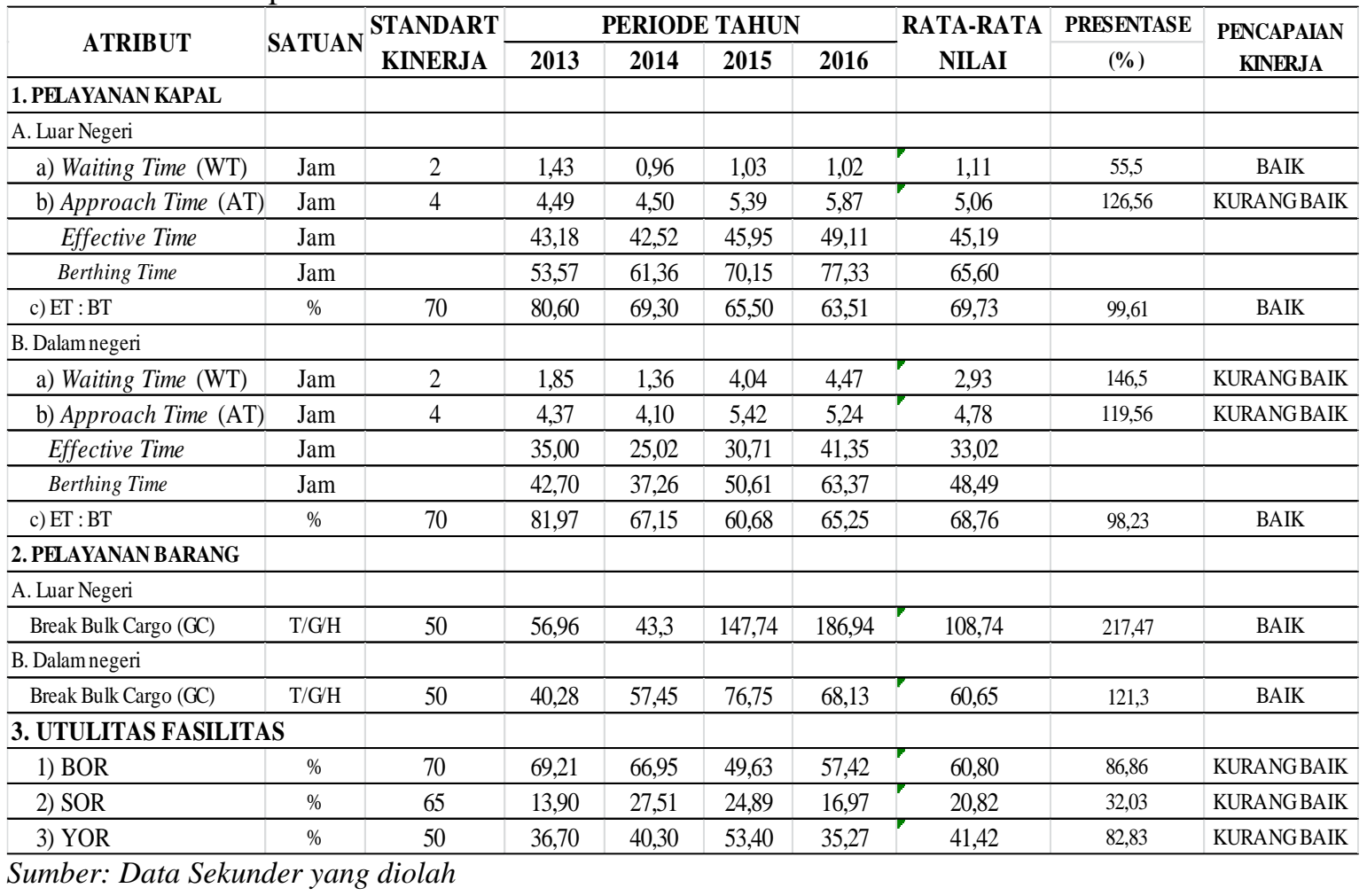

\subsection{Strategi Pengembangan Terminal Jamrud Dengan Metode Strengh, Weakness, Opportunity, Treath (SWOT) Dengan IFAS-EFAS}

Berdasarkan hasil penyebaran kuesioner dan wawancara kepada 160 responden dari berbagai pihak dan instansi yang berkaitan dengan operasional bongkar muat barang general cargo di Terminal Jamrud Pelabuhan Tanjung Perak, maka perumusan perbaikan kinerja operasional menggunakan Metode SWOT IFAS-EFAS. Jumlah responden terbesar adalah berstatus sebagai perusahaan pelayaran (PP) sebesar 26,25\%, kedua instansi perusahaan terkait lainnya sebesar $25 \%$, dan perusahaan bongkar muat (PBM) sebesar $21,25 \%$ sedangkan yang terendah adalah Ekspedisi muatan kapal laut (EMKL) sebesar $10 \%$. Keseluruhan responden berjenis kelamin laki-laki dengan usia responden 20-30 hingga 31-40 tahun sebanyak $63,75 \%$, sedangkan presentase responden untuk usia 41-50 tahun sebesar $23 \%$. Persentase pendidikan terakhir dengan tingkat pasca sarjana sebesar $11,88 \%$, tingkat sarjana dan Diploma sebesar 38,13\%. persentase rata-rata banyaknya muatan yang dibongkar sebesar 21-50 ton sampai dengan 51-70 ton yaitu sebesar $58,54 \%$, sedangkan presentase terendah dengan jumlah muatan $>100$ ton sebesar $12.80 \%$.

\section{Hasil Analisis SWOT Dengan IFAS- EFAS}

Sebelum merumuskan strategi Pengembangan kinerja operasional dengan matriks SWOT, terlebih dahulu akan disusun faktor strategi Internal dan Eksternal yang berpengaruh terhadap pengembangan kinerja Terminal Jamrud di Pelabuhan Tanjung Perak. Faktor-faktor tersebut diperoleh dari kajian literatur dan hasil wawancara kepada responden pengguna jasa di pelabuhan Tanjung Perak dapat dilihat seperti pada Tabel 2.

\section{Analisa Matriks IFAS}

Matriks IFAS digunakan untuk menganalisa faktor-faktor pada internal terminal. Berdasarkan hasil analisa Matrik IFAS maka yang menjadi kekuatan Terminal Jamrud dipakai 6 faktor dengan skor total faktor kekuatan internal sebesar 2,99 dimana dipakai bobot antara $0,15-0,18$ setiap itemnya dengan rating $2,00-4,00$, dan yang menjadi kelemahan Terminal Jamrud dipakai 5 faktor dengan skor total 2,23 dimana dipakai bobot 
antara $0,16-0,23$ setiap itemnya dengan rating $2,00-4,00$.

\section{Analisa Matriks EFAS}

Matriks EFAS digunakan untuk menganalisa faktor-faktor pada eksternal terminal. Berdasarkan hasil analisa Matrik EFAS maka yang menjadi peluang eksternal
Terminal Jamrud dipakai 6 faktor dengan skor total faktor kekuatan internal sebesar 2,99 dimana dipakai bobot antara $0,15-0,18$ setiap itemnya dengan rating $2,00-4,00$, dan yang menjadi kelemahan Terminal Jamrud dipakai 5 faktor dengan skor total 2,23 dimana dipakai bobot antara $0,16-0,23$ setiap itemnya dengan rating $2,00-4,00$.

Tabel 2. Matrix SWOT

\begin{tabular}{|c|c|c|}
\hline EFAS & \begin{tabular}{|l} 
Kekuatan (Strenght) \\
S1. Gudang penumpukan barang \\
$\quad$ yang memadai; \\
S2. Produktivitas bongkar muat \\
$\quad$ general cargo yang baik; \\
S3. Kolam pelabuhan cukup baik \\
S4. Memadainya Fasilitas Pelayanan \\
$\quad$ dokumen administrasi dan \\
informasi teknologi (IT); \\
S5. Jumlah alat bongkar-muat general \\
cargo; \\
S6. Tingkat keamanan barang cukup \\
baik
\end{tabular} & \begin{tabular}{|l} 
Kelemahan (Weaknesses) \\
W1. Peralatan Bongkar Muat yang \\
tidak sesuai dengan peruntukan; \\
W2. Panjang/jumlah dermaga masih \\
kurang; \\
W3. Waktu Tunggu kapal cukup lama \\
(Waiting Time) \\
W4. Waktu tunggu pandu cukup lama \\
(Waiting Time Pilot); \\
W5. Approach time cukup lama
\end{tabular} \\
\hline \begin{tabular}{|l} 
Peluang (Opportunity) \\
O1. Meningkatnya volume \\
bongkar dan Muat barang \\
O2. Kemudahan aksesibilitas \\
bagi armada truk; \\
O3. Luas lahan parkir truk \\
yang memadai \\
O4. Jumlah kunjungan kapal \\
mengalami peningkatan \\
yang signifikan. \\
O5. Minat Penggunaan \\
Lapangan penumpukan \\
oleh pengguna jasa
\end{tabular} & $\begin{array}{l}\text { Strategi }- \text { SO } \\
\checkmark \checkmark \text { Meningkatkan produktivitas } \\
\text { bongkar muat general cargo dan } \\
\text { memperdalam kolam pelabuhan } \\
\text { dikarenakan terus bertambahnya } \\
\text { volume bongkar-muat barang dari } \\
\text { meningkatnya kunjungan kapal di } \\
\text { dermaga Jamrud. (S1,2,3, O1,4) } \\
\checkmark \\
\text { Menambah alat atau } \\
\text { memaksimalkan stabilisasi dari } \\
\text { fungsi alat bongkar-muat barang } \\
\text { general cargo dan meningkatkan } \\
\text { tingkat keamanan barang saat } \\
\text { proses bongkt-muat muatan } \\
\text { mengingat minat penggunaan } \\
\text { lapangan penumpukan barang } \\
\text { oleh pengguna jasa yang terus } \\
\text { mengalami peningkatan, } \\
\text { sehingga diperlukan tersedianya } \\
\text { aksesibilitas yang mudah untuk } \\
\text { armada truk dan lahan parkir } \\
\text { yang cukup memadai. } \\
\text { (S4,5,6 O,2,3,5) }\end{array}$ & \begin{tabular}{|l} 
Strategi - WO \\
$\checkmark$ Menambah panjang/jumlah \\
dermaga dan menambah crew \\
awak pand kapal agar \\
mempercepat proses kegiatan \\
waiting time pilot, waiting time \\
dan approach time di dermaga \\
mengingat jumlah kunjungan \\
kapal yang terus meningkat \\
sehinga terjadi pula peningkatan \\
produktivitas B/M general cargo \\
(W2,3,4,5 O1,4) \\
$\checkmark$ Melakukan pegawasan terhadap \\
penggunan alat yang sudah tidak \\
sesuai SWL nya dikarenakan \\
aktivitas bongkarmuat barang \\
general cargo terus meningkat \\
dari tahun ke tahun (W1, O1)
\end{tabular} \\
\hline
\end{tabular}




\begin{tabular}{|c|c|c|}
\hline EFAS & $\begin{array}{l}\text { Kekuatan (Strenght) } \\
\text { S1. Gudang penumpukan barang } \\
\text { yang memadai; } \\
\text { S2. Produktivitas bongkar muat } \\
\text { general cargo yang baik; } \\
\text { S3. Kolam pelabuhan cukup baik } \\
\text { S4. Memadainya Fasilitas } \\
\text { Pelayanan dokumen } \\
\text { administrasi dan informasi } \\
\text { teknologi (IT); } \\
\text { S5. Jumlah alat bongkar-muat } \\
\text { general cargo; } \\
\text { S6. Tingkat keamanan barang } \\
\text { cukup baik }\end{array}$ & $\begin{array}{l}\frac{\text { Kelemahan (Weaknesses) }}{\text { W1. Peralatan Bongkar Muat yang }} \\
\text { tidak sesuai dengan peruntukan; } \\
\text { W2. Panjang/jumlah dermaga masih } \\
\quad \text { kurang; } \\
\text { W3. Waktu Tunggu kapal cukup lama } \\
\quad \text { (Waiting Time) } \\
\text { W4. Waktu tunggu pandu cukup lama } \\
\text { (Waiting Time Pilot); } \\
\text { W5. Approach time cukup lama }\end{array}$ \\
\hline $\begin{array}{l}\text { Ancaman (Treat) } \\
\text { T1. Produktivitas kinerja } \\
\text { TKBM yang masih rendah } \\
\text { T2. Jam kerja operasional } \\
\text { bongkar muat barang oleh } \\
\text { PBM kurang maksimal } \\
\text { T3. Kurang disiplinnya } \\
\text { pengguna jasa terhadap } \\
\text { prosedur dokumen barang; } \\
\text { T4. Faktor cuaca yang tidak } \\
\text { menentu; } \\
\text { T5. } \text { Tingkat pemakaian } \\
\text { dermaga yang cukup } \\
\text { tinggi (BOR) }\end{array}$ & $\begin{array}{l}\text { Strategi-ST } \\
\checkmark \text { Memperdalam alur pelayaran dan } \\
\text { kolam pelabuhan, menambah } \\
\text { fasilitas pelayanan yang berbasis } \\
\text { teknologi informasi serta } \\
\text { meningkatkan prosedur keamanan } \\
\text { bongkar-muat barang dan fasilitas } \\
\text { gudang penumpukan untuk } \\
\text { memaksimalkan kinerja } \\
\text { operasional kapal yang dipengaruhi } \\
\text { juga oleh faktor eksternal seperti } \\
\text { faktor cuaca yang tidak dapat } \\
\text { diprediksi (S3,4,6 T1,2,3,4) } \\
\text { Memaksimalkan kinerja alat } \\
\text { bongkar-muat barang untuk } \\
\text { menunjang kinerja TKBM yang } \\
\text { masih rendah demi menunjang } \\
\text { produkivitas dermaga }(\mathrm{S} 2,5 \mathrm{~T} 1,5)\end{array}$ & 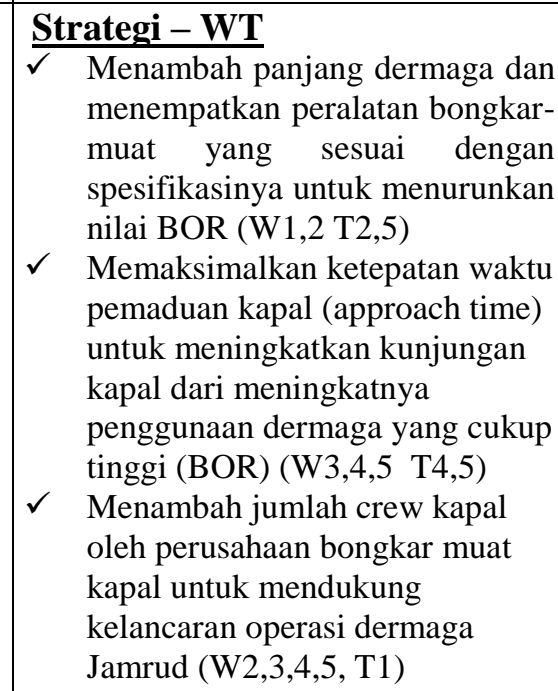 \\
\hline
\end{tabular}

Sumber: Hasil Analisis 2017

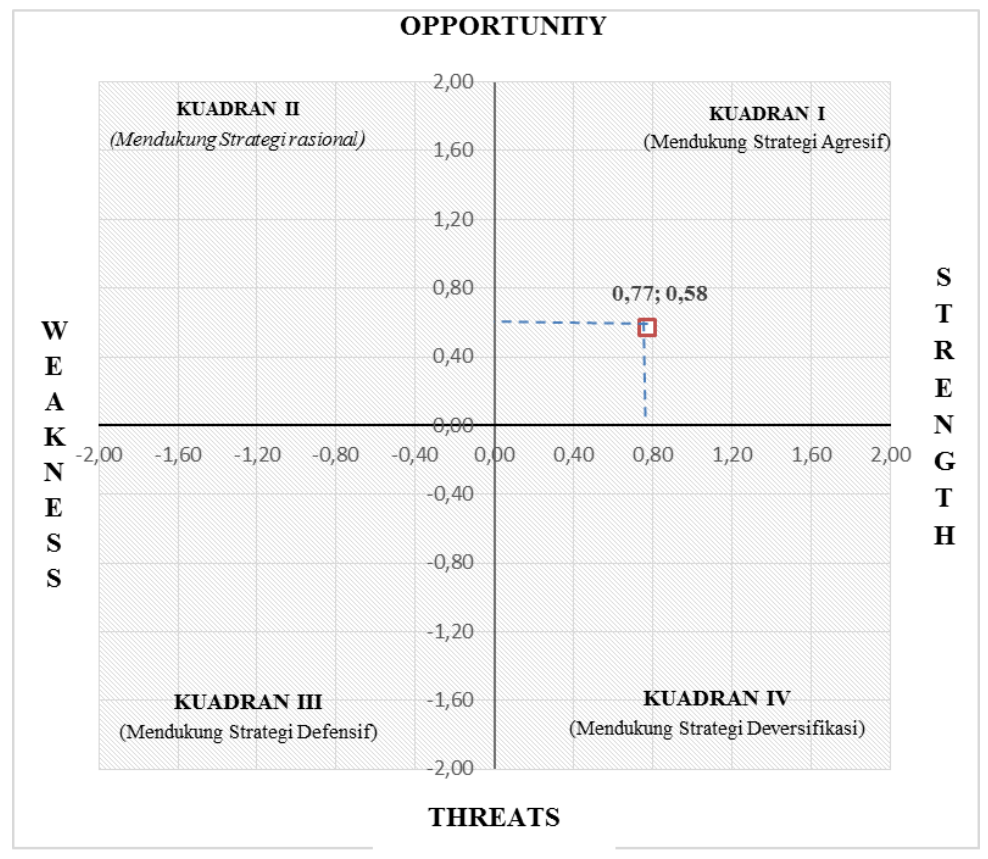

Gambar 4. Diagram kartesius hasil analisa matriks SWOT 


\section{Diagram Matriks SWOT}

Posisi strategi digunakan untuk menentukan pilihan pada keemapat strategi yang telah didapatkan oleh analisa matrik SWOT, yaitu cara menepatkan total skor pada faktor internal dan eksternal matrik.

Untuk mengetahui letak kuadran digunakan formulasi sumbu $\mathrm{x}$ dan sumbu $\mathrm{y}$, dimana sumbu $\mathrm{x}$ adalah EFAS (peluang - ancaman) dengan nilai sebesar 0,58 dan sumbu y adalah IFAS (kekuatan - kelemahan) dengan nilai sebesar 0,77 yang dinyatakan dalam nilai sesuai hasil scoring yang telah dilakukan. Adapun hasil dari analisis Matriks SWOT dapat dilihat pada Gambar 4.

Berdasarkan perhitungan SWOT, IFAS dan EFAS, yakni kekuatan lebih besar dari pada peluang yang ada, dimana arah kebijakannya adalah rapid growth strategy yang berarti pertumbuhan peran yang dilaksanakan dapat dilakukan dengan cepat (strategi agresif). Strategi untuk mengembangkan atau meningkatkan kinerja operasional bongkar-muat general cargo di Terminal Jamrud adalah:

1. Meningkatkan produktivitas bongkar muat general cargo

2. Memperdalam kolam perairan di pelabuhan

3. Menambah alat-alat produksi bongkar-muat sesuai dengan kebutuhan dan meningkatkan kinerja pengawasan dalam manajemen maintenance alat-alat produksi sesuai dengan SWL nya

\section{KESIMPULAN DAN SARAN 5.1 Kesimpulan}

Berdasarkan hasil analisa data dan pembahasan yang telah dilakukan dalam kajian ini, dapat ditarik kesimpulan sebagai berikut:

1. Berdasarkan kondisi eksisting dibandingkan dengan SK Dirjen Hubla Nomor HK/103/2/18/DJPL-16 Tahun 2016, pencapaian kinerja operasional Terminal Jamrud Pelayanan untuk tingkat kinerja paling baik adalah produktivitas bongkar muat general cargo dan untuk tingkat kinerja kapal paling baik adalah approach time. Sedangkan tingkat kinerja untuk Pelayanan waiting time kapal belum memenuhi pencapaian yang diharapkan karena masih berada di bawah standart yang ditetapakan serta utilitas dermaga terminal non petikemas, SOR dan lapangan penumpukan (YOR) masih harus diperbaiki lagi.

2. Diketahui dari hasil analisis SWOT EFAS dan IFAS didapatkan bahwa arah perbaikan dan pengembanganpada Terminal Jamrud dalam melayani bongkar-muat general cargo (GC) berada pada kuadran I (satu) yaitu strategi pertumbuhan (Growth) yaitu pada strategi pertumbuhan agresif (rapid growth strategy). Hal tersebut menunjukkan bahwa strategi yang dapat digunakan dengan memanfaatkan peluang untuk memaksimalkan kekuatan yang ada, adapun strateginya adalah sebagai berikut:

a. Meningkatkan produktivitas bongkar muat general cargo dan memperdalam kolam pelabuhan dikarenakan terus bertambahnya volume bongkar-muat barang dari meningkatnya kunjungan kapal di dermaga Jamrud.

b. Menambah alat atau memaksimalkan stabilisasi dari fungsi alat bongkarmuat barang general cargo mengingat minat penggunaan lapangan penumpukan barang oleh pengguna jasa yang terus mengalami peningkatan, sehingga diperlukan tersedianya aksesibilitas yang mudah untuk armada truk dan lahan parkir yang cukup memadai.

\subsection{Saran}

Berdasarkan analisa dan pembahasan yang telah dikemukakan pada bab-bab sebelumnya, maka kesimpulan dari hasil penelitian ini sebagai berikut :

1. Pengoptimalan alat-alat bantu produksi bongkar-muat sesuai dengan kebutuhan dengan cara penyewaan alat untuk menghemat cost bagi operator perusahaan yang dapat memperlancar operasional pelabuhan dan meningkatkan kinerja pengawasan dalam manajemen maintenance alat-alat produksi sesuai dengan SWL nya dan peruntukannya

2. Peningkatan pelayanan administrasi dengan sosialisasi kepada pengguna jasa dan mengoptimalkan sistem informasi teknologi secara publik yang terintegrasi melalui sistem National Single Windos (NSW) maupun melalui sistem online (inapornet) sehingga mengurangi permasalahan administratif di pelabuhan. 


\section{DAFTAR PUSTAKA}

[1] Kementerian Perhubungan, Ditjen Hubla (2016). Surat Keputusan Direktur Jenderal Perhubungan Laut NOmor : HK/103/2/18/DJPL-16 Tentang Standar Kinerja Pelayanan Operasional Pelabuhan Jakarta : Kementerian Perhubungan

[2] Kramadibrata, S. (2002). Perencanaan Pelabuhan. Bandung: Penerbit ITB.

[3] Lasse, D. (2012). Manajemen Muatan aktivitas Rantai Pasok Di Area Pelabuhan. Jakarta: RajaGrafindo Persada.

[4] Marzuki, S. (2008). Pengaruh Faktor Kelembagaan, Fisisk dan Eksternal terhadap Produktivitas Bongkar Muat Petikemas. DIEJurnal ilmu Ekonomi dan Manajemen, 129-173.

[5] Rangkuti, F. (2005). Metode SWOT. Jakarta: Gramedia Pustaka Utama.

[6] Sugiono. (2014). Metode penelitian Kuantitatif Kualitatif dan R \& D. Bandung: Alfabeta.

[7] Triatmodjo, B. (2010). Perencanaan pelabuhan. Yogyakarta: Beta Offset.

[8] UNCTAD. (2015). Review of Maritim Transport. New York and Guwena: United Nation Publication 